\title{
We are our choices
}

\author{
Tony Delamothe deputy editor, The BMJ
}

As the fog of post-election hyperbole lifts, the NHS is still there and still beset by the same pre-election problems. Anyone remaining hazy as to what these are should read the editorial by Chris Ham (doi:10.1136/bmj.h2541), who is one of the country's most authoritative guides to the NHS.

"Failure to provide further funding beyond current plans either means accepting growing deficits within the NHS, or insisting that NHS organisations reduce their costs to live within available budgets," writes Ham. "This may require unpalatable choices such as cutting back on staff or reducing activity—with effects on quality of care and waiting times."

The alternative, improving productivity to realise $£ 22 \mathrm{bn}$ ( $€ 31 \mathrm{bn}$; $\$ 35 \mathrm{bn}$ ) in efficiency savings, is unlikely by the end of this parliament. Instead, care will have to be transformed, concludes Ham. This looks like being the NHS's main challenge for the next five years.

Choosing Wisely, a clinically led initiative from the United States, could help (doi:10.1136/bmj.h2308). As Aseem Malhotra and colleagues from the Academy of Medical Royal Colleges explain, this programme aims to stop doctors using tests or procedures unsupported by evidence. It begins with medical organisations compiling lists of the five interventions that should be stopped in their specialty. So far 60 US specialist societies have joined the initiative, and the model has been adopted by several other countries.

One might wonder why this "no brainer" has taken several years to reach our shores. Still, enough time has elapsed for the identification of problems elsewhere, such as the reluctance of some specialists to threaten revenue heading towards their pockets. The BMJ is throwing its weight behind Choosing Wisely, as part of our Too Much Medicine campaign (www. bmj.com/too-much-medicine).

Change has also been afoot in the intermittently febrile world of general medical journals, with one editor escorted off the premises by human resources and another the subject of a petition for his removal. Stephen Leeder was fired as editor in chief of the Medical Journal of Australia because he disagreed with the decision of its owner to outsource production of the journal to Reed Elsevier, the world's largest scientific publisher. Richard Smith, a former editor of The BMJ, provides an informed commentary on the shenanigans (bmj.co/1e1sS6n).

Richard Horton, current Lancet editor, is not going anywhere just yet. Horton has taken a longstanding interest in the health of people in the occupied Palestinian territories, publishing a series on the topic in 2009. In July 2014, two weeks into Israel's latest military operation in the Gaza Strip, the Lancet published an open letter for the people of Gaza, "denouncing what we witness in the aggression of Gaza by Israel." The Lancet's handling of criticisms of the open letter, and particularly the undeclared competing interests of some of its 24 signatories, has left many angry. Some 400 physicians and scientists, headed by five Nobel laureates, have now accused the Lancet's publisher, Reed Elsevier, "of irresponsible and unethical business practice-profiting from the publication of dishonest and malicious material that incites hatred and violence."

In their editorial this week, John Yudkin and Jennifer Leaning look at some of the factual claims made in the open letter-and find that multiple sources support them (doi:10.1136/bmj. h2377). Yudkin and Leaning characterise the Lancet's accusers as bullies, intent on closing down debate on Israel's actions. "Yet to avoid such debate is to remain obdurately silent in the face of important trends and events that impact negatively on the wellbeing of individuals and groups," they say. "Inevitably, controversy will ensue, but this is a healthy aspect of public discourse on political matters."

Who could disagree?

Cite this as: BMJ 2015;350:h2609

๑ BMJ Publishing Group Ltd 2015 